\title{
Thwarted visions of change: power and demographics in repair cafes and urban sustainability transitions
}

\author{
Elena Schägg, Stefanie L. Becker *ib and Prajal Pradhan
}

\author{
${ }^{*}$ Correspondence: \\ slbecker@pik-potsdam.de \\ Potsdam Institute for Climate \\ Impact Research (PIK) e. \\ V, Telegrafenberg A 31 \\ 14473 Potsdam, Germany
}

\begin{abstract}
Sustainability initiatives, such as Repair Cafes, are sites of niche innovations with the potential to contribute to an urban sustainability transition. Using the multi-level perspective as a framework, we explore the visions of change of 12 Repair Cafes in Berlin to understand how the members believe the movement can effect change. We explore the dynamics and demographics of the different user groups within the Repair Cafes to understand who has a voice within them. We found that Repair Cafes have two main visions of change which ask for mass participation. However, we also found that latent discrimination by 'expert'technician volunteers discourages the involvement of women and lower social classes. This knowledge that Repair Cafes are inconsistent in their purported visions of change and their practices has repercussions for their role in urban sustainability transitions.
\end{abstract}

\section{Highlights}

- Repair Cafes envision a transition where as many people as possible participate in repair activities.

- The roles and hierarchy within the Repair Cafes lead to power differentials.

- The roles within Repair Cafes lead to women and lower classes being discouraged from participation.

- Repair Cafes are inconsistent between their visions of change and their practices.

- Current Repair Café practices hurt their ability to contribute to a transition.

Keywords: Repair Café, Sustainability, Transitions, Discrimination, Sexism, Sociotechnical transitions

\section{Policy and practice recommendations}

- Repair Cafes should invite more women and minorities to become volunteers.

- Repair Cafes should actively teach repair to visitors with a particular focus on female visitors. author(s) and the source, provide a link to the Creative Commons licence, and indicate if changes were made. The images or other third party material in this article are included in the article's Creative Commons licence, unless indicated otherwise in a credit line to the material. If material is not included in the article's Creative Commons licence and your intended use is not permitted by statutory regulation or exceeds the permitted use, you will need to obtain permission directly from the copyright holder. To view a copy of this licence, visit http:// creativecommons.org/licenses/by/4.0/. 
- Funders and facilities hosting Repair Cafes could encourage them to undertake actions that would be inclusive.

- Visitors should be allowed more say in how the Repair Cafe functions and thus more power.

- Having someone within the Repair Cafe who is responsible for advocating for women, minorities, and lower social classes.

\section{Introduction: Repair Cafes and urban sustainability transitions}

Cities and urban spaces, with their distinctive collection of social, political, technological, and economic factors, have been acknowledged as sites of unique transformational potential (Loorbach and Shiroyama 2016; Frantzeskaki et al. 2017; Pradham et al. 2020). Within the context of climate change, the need for a transition to a more sustainable society is widely acknowledged and the unique properties of urban spaces allow for potential innovations to flourish (Bulkeley et al. 2010; Fuenfschilling et al. 2019).

Community-based initiatives (also sometimes referred to as grassroots initiatives or grassroots innovation movements) are sites of experimentation and innovation with the potential to help transition to a more sustainable society (Seyfang and Smith 2007; Seyfang 2010; Smith et al. 2013; Seyfang and Haxeltine 2012; Hargreaves et al. 2013). They allow for climate change action to be determined by the members of the community which is thought to be not only powerful but essential (Devine-Wright 2013; Hargreaves et al. 2011) while addressing the wider problem of a need for a sustainability transition.

One type of community-based initiative is the Repair Café. Repair Cafes are selfdescribed as 'free meeting places and they're all about repairing things (together)' (Stitching Repair Café 2017). People can bring broken furniture, electrical appliances, bicycles, and more to the Repair Cafes and find tools and materials to fix them. They can also make use of the help of expert volunteers who guide the repair work. Repair Cafes offer a potential avenue of achieving SDG 12 (Responsible Consumption and Production) through displaying a potential alternative to our current single-use economic regime. However, community-based initiatives, such as Repair Cafes, are contested sites (Smith and Raven 2012) where different ideas, directions, and practicalities clash. They often display inconsistencies between their actions and their stated goals, such as claiming to want to reduce food waste while creating a way for grocery stores to legitimize it (Argüelles et al. 2017). The stated goals of Repair Cafes are influenced both by the narratives of change of the members, which is influenced by who participates in the initiative, as well as their ability to affect within the initiative and thus highlights any unequal power dynamics the members have within the organization. While research into the potential of community-based initiatives is on the rise (Schäfer et al. 2018; Landholm et al. 2019; Celata et al. 2019), research into how internal power dynamics influence the ability of these initiatives to contribute to a transition is still lacking.

Thus, the overarching objective of this article is to answer the question 'What does the way Repair Cafes envision and practice their movement mean for their potential to contribute to multiple domains of a niche-lead urban sustainability transition?' We will fulfill this objective by addressing the following research questions. 
1. What are the narratives of change expressed by participants of Repair Cafes and how do they compare with socio-technical transition literature?

2. Who participates in the Repair Cafes and what positions do they hold?

3. What does the relationship between who participates and what position they hold mean for the ability of the Repair Cafe to achieve their narrative of change?

To address these research questions, this article will first explore how Repair Cafes fit into existing theory on transitions, gender, and power (Transitions, power, and gender section). Secondly, we will explain how both qualitative and quantitative data were collected from Repair Cafes in the German capital of Berlin and used to arrive at the results (Mixed method approach section). Thirdly, we will examine the different narratives of change expressed by the members of Repair Cafes (Competing narratives section), who participates in Repair Cafes, and what roles they fill in the Repair Cafes (Participants and their roles section). Fourthly, we will scrutinize the inconsistencies between the Repair Cafes visions and actions, and discuss what they mean for the potential of Repair Cafes to contribute to multiple dimensions of a sustainable transition (Discussion section) before finally offering suggestions for improving the ability of Repair Cafes to contribute to a sustainable transition (Recommendations and further researchsection).

\section{Transitions, power, and gender}

The multi-level perspective is a process theory (Grin et al. 2010) that explains and narrates the process through which a society can go from our current unsustainable state to a more sustainable one (Markard and Truffer 2008). It consists of three levels situated within a 'nested hierarchy' (Geels 2005, p. 684) of structuration (Geels 2004; Verbong and Geels 2007). The least structurized of these levels, the niche, can be understood as sites of experimentation and innovation embedded within the local context. This is where community-based initiatives such as Repair Cafes experiment with new ideas which offer alternatives to current practices (Geels 2002). If Repair Cafes as community-based initiatives are willing and able to upscale and spread their practices they can challenge the next level, the regime. The regime consists of current practices (such as lifestyles, user practices, institutional arrangements, and regulations) and 'rules of the game' (Smith 2003, p. 3) and is the dominant power constellation (Avelino and Rotmans 2009). The last level in the hierarchy is the landscape which consists of 'deep structural trends' (Geels 2002, p. 1260) such as the historic, cultural, and environmental backdrop (Geels 2011; Rotmans et al. 2001). For a transition to occur, a niche must become institutionalized enough to challenge the regime (Geels 2014). The multi-level perspective is used within the paper to understand the potential role of Repair Cafes as niches within a transition.

There are four pathways for a transition to occur as described by Geels and Schot (2007: 1) the 'transformation pathway' where social groups such as Repair Cafés can display alternatives and demand that regimes adopt them. 2) The 'de-alignment and realignment path' where a shock disrupts the regime when none of the Repair Cafes are developed enough to successfully challenge the regime alone leading to several niches coexisting until one eventually wins. 3) The 'technological substitution' where the Repair Cafe is sufficiently developed when a shock occurs to the regime allowing the niche to 
replace it. 4) The 'reconfiguration pathway' where the regime adopts parts of the niche, in this case, the Repair Café's innovation.

However, not all individuals that participate in the Repair Café movement have the same opportunity to contribute and influence the Repair Cafe. The concept that will inform our analysis on who has a voice within the Repair Cafes is called hegemonic masculinity. It is a sociological theory of gender relations that is "understood as a pattern of practice...that allowed men's dominance over women to continue" as well as over subordinate men (Connell and Messerschmidt 2005). Within this understanding of gender relations, there are multiple masculinities and femininities. The hegemonic masculinity is both normative and "the current most honored way of being a man" (Connell and Messerschmidt 2005). Hegemonic femininity "consists of the characteristics defined as womanly that establish and legitimate a hierarchical and complementary relationship to hegemonic masculinity and that, by doing so, guarantee the dominant position of men and the subordination of women." (Schippers 2007). There are also non-hegemonic masculinities that are seen as not the most ideal way of performing maleness.

According to Avelino and Rotmans (2009) there are four types of power within a transition which we will use to explore the power of the Repair Café user groups: 1) innovative power, the ability of user groups to create new resources 2) destructive power, the ability of user groups to destroy resources 3) transformative power, the ability of user groups to transform the distribution of resources, and 4) systematic power, the ability of user groups to mobilize for the survival of the system.

\section{Mixed method approach}

To answer our research questions, we used a mixed method approach (Flick et al. 2010), using both qualitative and quantitative data gathered from a survey and semi-structured interviews (Data section). We analyzed the data using both quantitative (Descriptive statistical analysis section) and qualitative approaches (Coding section).

\section{Data}

We examined 12 Repair Cafes from a variety of districts in Berlin, Germany. Berlin was chosen as a geographical area of this study because it can be considered an area of "fertile soil" (Sekulova et al. 2017) as shown by its more than 220 initiatives in the area of repair, reuse, and lending (REMAP 2018). Repair Cafes with diverse aims and activities were chosen as case studies. For this article, we adapted the Becker et al. (2018) definition of community-based initiatives:

"one or more individuals working together embedded in the community or grassroots that do the work of experimenting and institutionalizing novel grassroots innovations and whose work directly or indirectly has the potential to support a transition" (Becker et al. 2018).

We have then modified it so that we define Repair Cafes as groups of one or more individuals experimenting with novel repair-centered grassroots innovations.

We conducted a theoretical sampling of Repair Cafes belonging to one of the two Repair Cafes networks, Stitching Repair Café (2017) and Reparatur-Initiativen (2018), 
ensuring that the chosen Repair Cafes were spatially distributed throughout the city of Berlin as well as were of diverse ages.

At the time the study was conducted, there were 32 Repair Cafes in Berlin belonging to one of two Repair Café Networks (Stitching Repair Café (2017), Netzwek Reparatur-Initiativen (2017). Twelve Repair Cafes were chosen from different areas of the city to participate in the quantitative survey; 6 from inner districts of Berlin and 6 from the outer districts of the city. Of the 12 Repair Cafes, we asked 3 to participate in the qualitative interviews. These three were selected based on their belonging to the Repair Café networks (one belongs to Netzwek Reparatur-Initiativen, one to Stitching Repair Café, and one belongs to both) as well as the age of the initiative (at the time of study one initiative was less than a year old, one was 3 years old, and one was 2 years old).

We conducted a survey of 81 participants at the 12 Repair Cafes in which both qualitative and quantitative data were collected that included questions such as "What is your highest educational achievement?" and "how many times have you visited a Repair Café?" We frequently handed out the survey at Repair Cafe events which allowed for a wide selection of those who participated in the Repair Cafe.

Semi-structured interviews were completed with 10 participants from 3 Repair Cafes which included questions such as "Could you please tell me a bit about yourself, and your role in this initiative?" and "Some people say that sustainability initiatives like Repair Cafés can contribute to a bigger social and political change. What do you think about it?" Interviewees were initially selected via a snowball sampling (Misoch 2015) starting from the initial contact with the Repair Café including specifically at one point asking for a female interviewee since the interviewees put forward were male. An additional 3 interviewees were approached directly at Repair Café meetings to better understand the viewpoint of those who came to the Repair Café but were less familiar to the regular attendees. The semi-structured interviews aim was to allow us to collect detailed and in-depth information whereas the survey allowed us to easily collect data from a larger number of participants. Care was given that the participants in the interviews held diverse positions within the Repair Cafes including organizers, volunteers, and visitors (these roles are detailed in Participants and their roles section). We conducted all interviews in German and interviewees gave their informed consent. We conducted both the survey and semi-structured interviews between 27/05/2017 and 30/06/2017. A list of interviews is given in Appendix.

In addition to the questionnaire and interviews, we took field notes during interviews and 12 participation observations. The field notes included individual impressions and circumstances of the interview and were included in the analysis. The 12 participation observations, one for every Repair Café, took place wherever the Repair Café normally met and included both internal Repair Café meetings as well as open repair events. Information we included in the observations included, for example, the purpose of the event, attendees, the origin of the initiative, atmosphere, interactions between attendees, repair objects, and other events of the initiative. Since the quantitative surveys were handed out at these 12 events, the researcher often received immediate feedback on the surveys as well as discussions with those who wanted to elaborate on their answers. The field notes were coded along with the other data. 


\section{Descriptive statistical analysis}

We analyzed the collected empirical data statistically. To do this, we digitized the handfilled questionnaires into a data matrix. The data was debugged when it consisted of mistakes of the respondents, e.g. invalid values when automatic filtering was used or wrongly entered values (indication of more than three asked motivation factors). We confined the statistical analysis to descriptive statistics. The main purpose of descriptive statistics is to present the gathered information in a clear way to either compress or reduce information (Raithel 2008). The statistical survey in this study aimed to describe the social backgrounds and the different experience values of the participants, thus, compressing information. Therefore, we considered the implementation of descriptive statistics as sufficient.

\section{Coding}

The qualitative data was analyzed in MAXQDA software to code themes and develop memos (Glaser 1998, 2007). We coded the first five interviews and the field observations openly and started with the first comparison of them by merging the codes into main categories. Following that, the interview guidelines were adapted by erasing and adding some questions to capture additional dimensions of this topic in sustainability initiatives during the additional five interviews and a discussion held in one Repair Cafe. These new interviews were coded openly before we completed a second selective coding and the first memos were written. These memos were then combined with the findings from the descriptive statistics to analyse the situation within the Repair Cafes. By going back to literature, the author specified core categories, and then subsequently, we carried out the theoretical coding.

Each of the three qualitative case study Repair Cafes was given a descriptive pseudonym (Table 1) to protect the anonymity of the cafes and the interviewees.

\section{Results}

\section{Competing narratives}

In this section, we explore the different narratives of change expressed by the interviewees for the Repair Cafes and describe how the work of Repair Cafes will lead to

Table 1 Given pseudonym and description of case study Repair Cafes

\begin{tabular}{|c|c|}
\hline Pseudonym & Description \\
\hline Green Repair Cafe & $\begin{array}{l}\text { Started in June 2014. Around } 20 \text { active volunteers of which many have been engaged } \\
\text { with the Repair Cafe from the beginning. The Repair Cafe opens its doors once a month } \\
\text { for } 3 \text { h. Visitors have to register in advance and the number varies between } 18 \text { and } 25 \\
\text { visitors each meeting. The Repair Cafe was founded and is still managed by a staff mem- } \\
\text { ber of a local environmental NGO. }\end{array}$ \\
\hline Organized Repair Cafe & $\begin{array}{l}\text { Started in October } 2016 \text {. The same } 14 \text { volunteers attend every month. The Repair Cafe } \\
\text { opens its doors once a month for } 3 \text { h. Visitors have to register in advance and, after } \\
\text { consultation with the organizer, indicate the specific device's problem. In consequence, } \\
\text { the exact repair time can be assessed, thus this Repair Cafe can invite } 25 \text {-30 visitors each } \\
\text { meeting. }\end{array}$ \\
\hline Bike Repair Cafe & $\begin{array}{l}\text { The idea for the Repair Cafe was born in January 2015, but the initiative had to change } \\
\text { places and meeting times until it could find a more permanent meeting place in an } \\
\text { inner district in Berlin in September } 2015 \text {. The Repair Cafe pays rent to a social 'share- } \\
\text { house'. The Repair Cafe has } 7 \text { founders and about } 30 \text { technical volunteers who come } \\
\text { regularly. }\end{array}$ \\
\hline
\end{tabular}


societal change answering the research question, "What are the narratives of change expressed by participants of Repair Cafes and how do they compare with sociotechnical transition literature?" These narratives are anti-regime and have the same frame of consumer criticism noted by Kannengießer (2018). As several interviewees explained:

"Throwaway society blames the society. For me, it is more a throwaway production that does not produce in a sense that enables repair" (FN13).

"What I see there is that we voluntarily made ourselves slaves of the monetary moment. Essentially, it was always like that but not on that global scale as it is right now" (IN7).

Interviewees generally felt that a sustainable society would come about through individuals changing their behavior and that Repair Cafes offer a platform for inducing that change. As one interviewee explained, 'When [the people] go home, they are definitely better informed and mostly happy. Then they disseminate this [the idea of repairing items]' (IN2). Through individuals joining the Repair Cafe, they envision their movement spreading. Beyond this, the narratives of change the interviewees described generally fell into two camps: (1) those who believe a change in the regime will come from their movement growing which we will call 'the niche growth narrative' and (2) those who believe the change in the regime will come from external pressures on the regime which we will refer to as 'the external shock narrative.' Both of the narratives were present in all of the Repair Cafes and sometimes both were present within one interview (such as IN2, IN7, IN10).

The first vision of change, the niche growth narrative, is contingent upon the Repair Cafes reaching as many people as possible. 'I think if everybody is mending his stuff then it wouldn't take long to start seeing effects like what consumers want. They don't want disposable things.' (IN10). This narrative argues that the pure existence of the Repair Cafe movement and the number of people who participate in the movement shows dissatisfaction with the current regime. Policymakers will pick up on this dissatisfaction and, by acting as representatives of those people, design policies that force manufacturers to undertake more sustainable practices and decouple them from pure economic interests (IN7). These new policies will result in more repair, potentially through producing longer-lasting products or through people being encouraged to repair, thus acting as a countervailing force to the current regime of planned obsolescence.

As a result of this narrative, they see the number of participants as reflective of the movement's influence and ability to contribute to a transition. Thus, when asked, $81 \%$ of respondents to the survey would prefer as many people as possible participating in Repair Cafes, even if that participation was superficial and short term. However, interviewees felt that at the moment the Repair Cafes did not have enough members to cause change (IN1, IN2, IN6, IN5). As one interviewee described it:

'The people who are interested use and know about [sustainability alternatives], but what percentage is this? Maybe three percent. The rest continues to throw away their smartphones'(IN9). 
Nonetheless, most interviewees believed that Visitors to Repair Cafes will spread the idea of repairing items to their friends and family. This belief is also reflected in that $88 \%$ of total respondents to the survey predicted that the movement will grow in the next 5 years.

The second vision of change, the external shock narrative, was more critical of the Repair Cafe movement leading to change. Thus, while interviewees articulating this narrative believed people would join the Repair Cafe movement as an expression of dissatisfaction with the regime, they did not believe that policymakers will respond to this. Instead, they believed that the regime is so entrenched that industry and policymakers will continue to ignore the Repair Cafe movement and only an external shock could cause regime actors to change their ways. One interviewee described her view:

'The construct of the human being, how I call it, is not [a precautionary thinker]. It only starts acting when seeing the abyss and even then it is difficult' (IN7).

In particular, those who push this narrative believe that policymakers will only respond to an external shock outside of the Repair Cafe movement and express a general disillusionment with the regime. One interviewee suggested rising prices because of depleting resources would make repairing items more appealing and could be one potential shock (IN10). However, some interviewees believed that even with an external shock to the system, current regime actors would still have a much larger say in the outcome due to power dynamics (IN9) and thus an external shock is not a guarantee of a transition towards more repair.

\section{Participants and their roles}

Since the number of participants is highlighted by both narratives of change, we explored who participates in Repair Cafes and what role they perform. Repair Cafes consist of hierarchies with differentiated roles, responsibilities, and voice. The Repair Cafes exist within the context of the current regimes and they thus often reflect the same power structures; namely, they are dominated by privileged hegemonic masculinities which have more of a voice within the organization than non-hegemonic masculinities or femininities. The roles within a Repair Cafe case roughly be divided into 3 role categories based on roles identified by the interviewees as well as observations: organizers, volunteers, and visitors. These roles within the Repair Cafe were quite inflexible and moving between these roles within most Repair Cafes was unusual.

The position of organizer was held somewhat equally among men and women (Fig. 1a) and is somewhat more often held by younger individuals (see Fig. 1c). Although the position of organizer within an organization is a position of power as they assign tasks to others, this position was not considered desirable by the interviewees because of the perceived time commitment. The organizers generally received little to no help from the volunteers or visitors in the administrative tasks of the Repair Cafe. However, as they were the sole organizer of the Repair Cafes, they had immense control of the direction of the Repair Cafes and the volunteers did not question that authority in interviews nor were they observed challenging it during participant observations.

The second position within Repair Cafes is volunteer, which is a position that requires working together on a team. Volunteers can generally be divided into two 

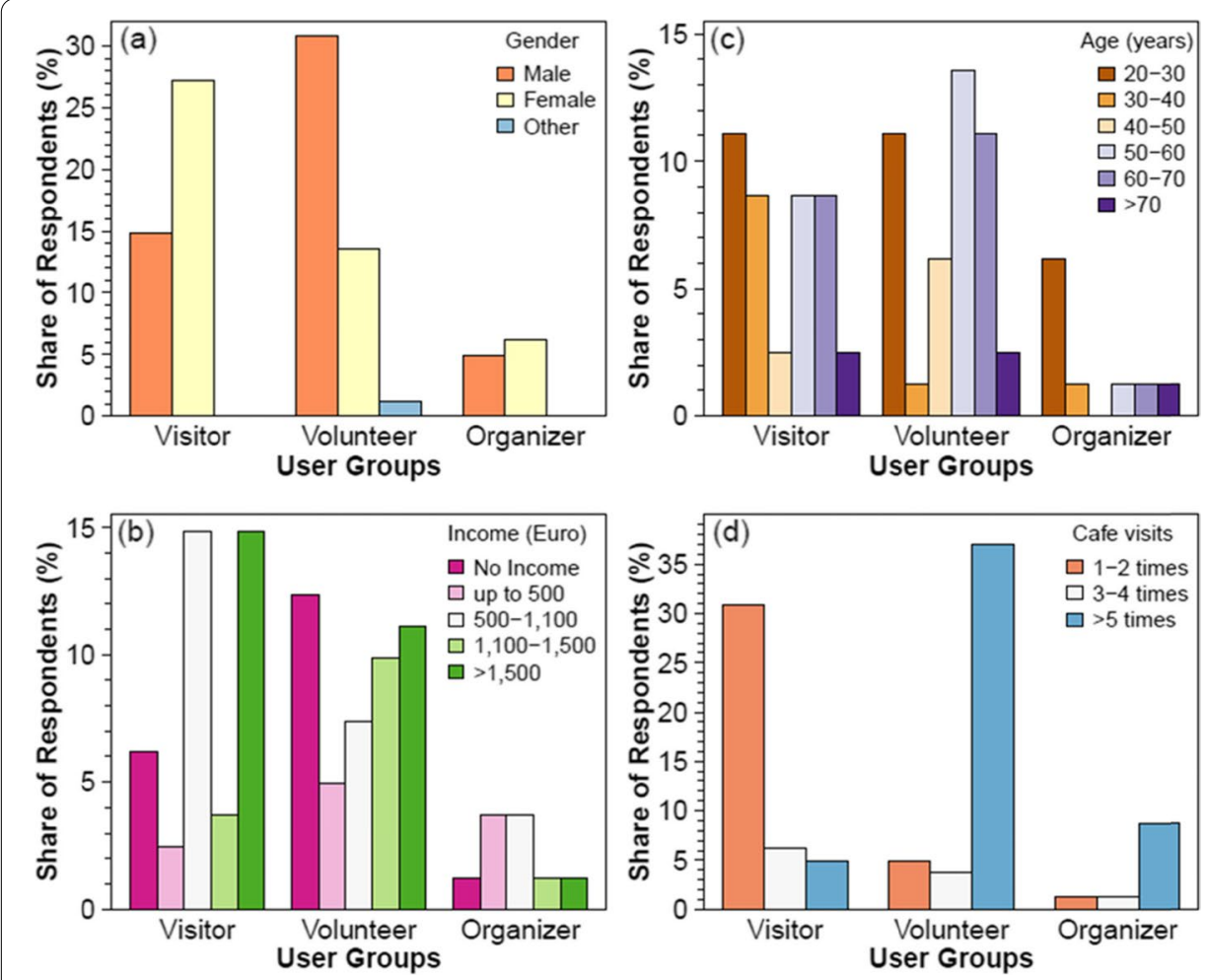

Fig. 1 Demographics and frequency of visits to a Repair Cafe. Chart (a) share of respondents in each user group by gender. Chart (b) share of respondents by user group by income. Chart (c) share of respondents by user group by age. Chart (d) share of respondents by user group by how many times they have visited the Repair Cafe

groups: technician volunteers who act as 'experts' work on repairing items and organizational volunteers who set up food and other necessities. However, while the technician volunteers were present in all Repair Cafes, only 4 Repair Cafes had organizational volunteers. The technician volunteer work is often mentally challenging and rewarding with the volunteers learning from other disciplines and attempting tricky repairs. These volunteers saw the Repair Cafes as a place to socialize with like-minded individuals and find self-affirmation. The volunteers in a Repair Cafe can become close:

'Over time a fixed team has developed. Everybody knows each other and sometimes you meet outside the Repair Café' (IN1).

Volunteers were more likely to have a negative view of the impact of their Repair Cafe and were more likely to express the 'external shock narrative' than other positions. The volunteers were more educated than any other user group (Fig. 2). Most volunteers cited empowerment as a reason for volunteering and $21 \%$ of volunteers who responded to the survey listed learning about repair as their motivation for participating in a Repair Cafe (Fig. 3). In the words of one volunteer: "[It is about] empowerment. Just teaching the people how to have fun with repair and help to overcome existing fears" (IN2). Volunteers had some say in the direction of the Repair Cafes and at least 3 Repair Cafes held annual meetings for the volunteers, however, 


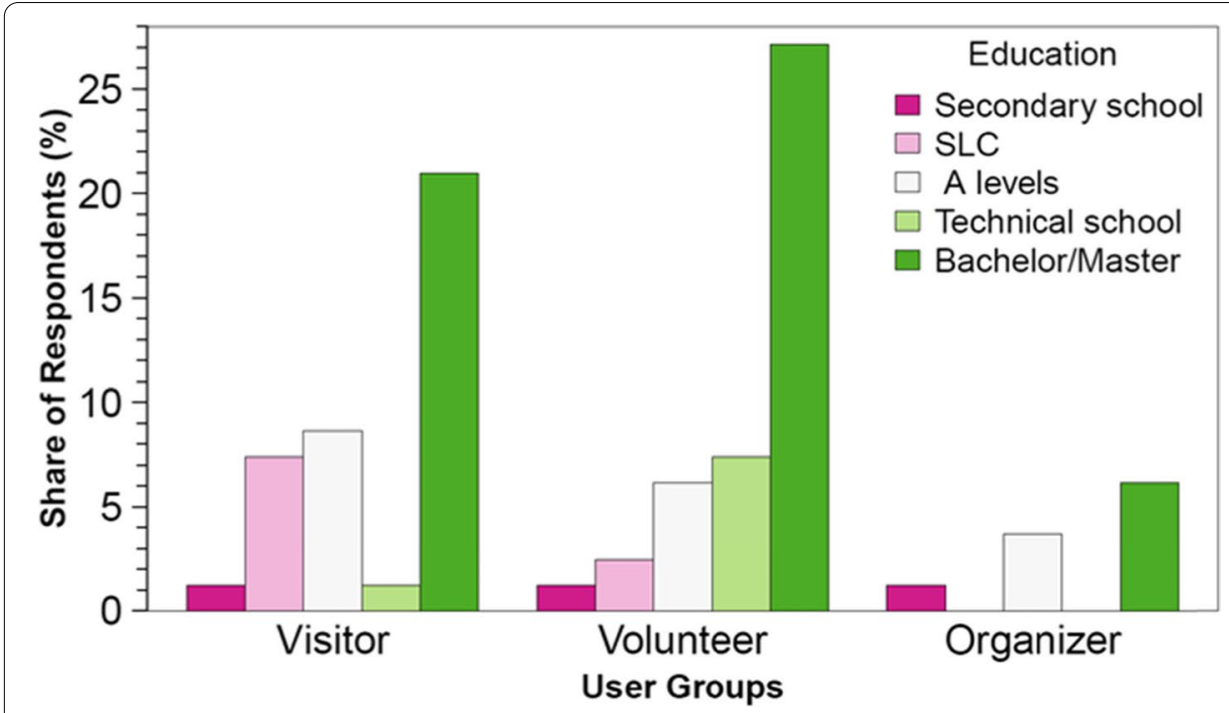

Fig. 2 Education attainment by share of respondents and user group

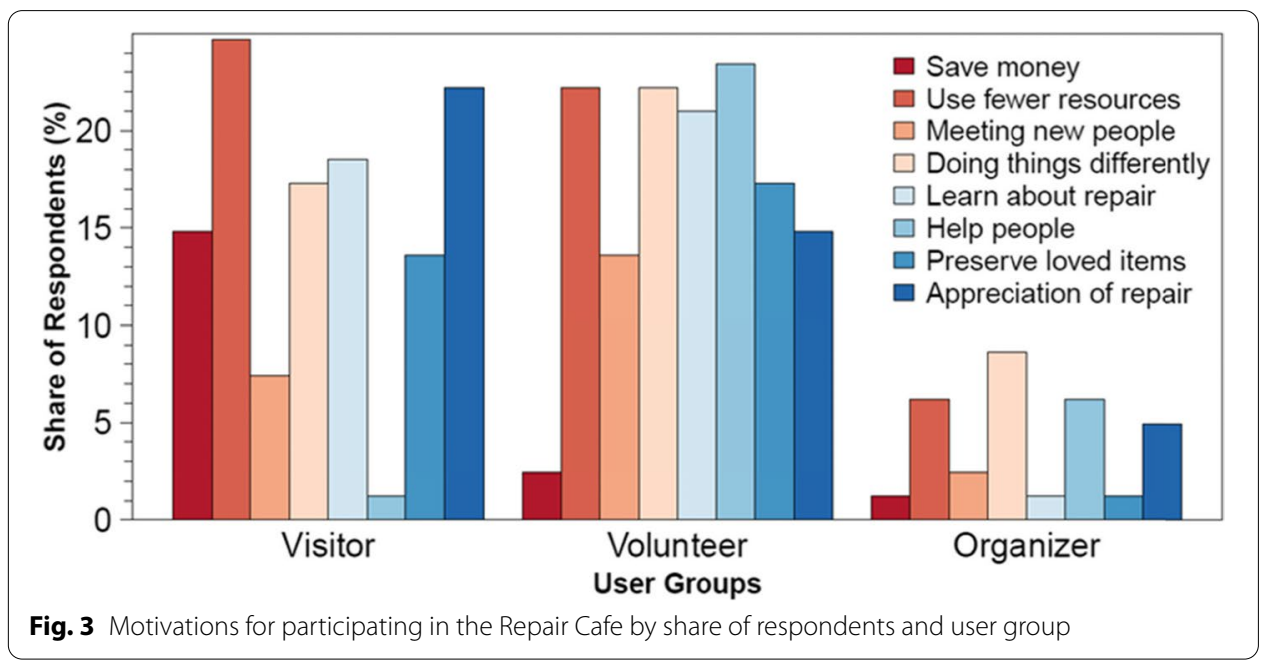

interviewees did not describe any tools the organizers used to identify the needs of the visitors.

The last position held within the Repair Cafes was that of visitor. In most Repair Cafes the visitors had very little say in the running and development of the Repair Cafe. In some Repair Cafes, the only way for a visitor to have input into the Repair Cafe was through feedback forms (Green RC, RC 9). Otherwise, the visitors were generally excluded from decision processes, with the exception being the Bike Repair Cafe as they organize more meetings and get-togethers that included visitors.

While it was theoretically possible for a visitor to become a volunteer within all of the Repair Cafes, it was only reported in three cases (Green RC, Organized RC, and RC 9) where visitors moved from a passive role as a consumer of the Repair Cafe's services to more active involvement within the Repair Cafe. For the visitors at the other Repair 
Cafes, the interaction with other positions is transactional and visitors only visited the Repair Cafe when they needed something repaired. Many visitors had a more optimistic opinion of the future of Repair Cafes than the volunteers and were impressed that people are engaging and making their contribution to a more sustainable society (FN1, FN5, IN4, IN7). Visitors were less likely to feel a sense of belonging to the Repair Cafe (46\%) compared to $85 \%$ of volunteers and $71 \%$ of organizers who responded to the structured interview.

In most of the Repair Cafes (except the Bike Repair Cafe), the organizers and volunteers spoke of their Repair Cafe community as not including the visitors. Nonetheless, when probed as part of the in-depth qualitative interviews it became clear that the visitors often had some repair knowledge and thus could potentially contribute to the Repair Cafes movement not only through becoming an organizational volunteer, but also a technician volunteer. The visitors who participated in the qualitative interviews commented that they while had some repair experience, they lacked either knowledge of certain technologies or tools (IN4, IN7). As one interviewee explained:

I could always do a lot of [repair] things by myself. But due to the new technologies I notice more and more that I am not able to do some of those repairs and I also lack the courage' (IN4).

This shows that many of the visitors are performing the role of the non-expert in need of the 'expert' technician volunteer to help them. Visitors were also more likely to say they visited the Repair Cafe to save money and less likely to say they visited a Repair Cafe to help people or to meet new people (Fig. 3).

There are significant demographic differences between the user groups of the Repair Cafes and that plays into the power relationship among them. In particular, volunteers were disproportionately male whereas visitors were disproportionately female with $59 \%$ of visitors stating they were female while $73 \%$ of volunteers stating they were male (Fig. 1a). Moreover, none of the female respondents to the survey reported that they felt like they had sufficient contact with the Repair Cafe compared to $18 \%$ of the male respondents (Fig. 4) and female respondents were more likely than male respondents in the survey to claim they had no interest in further participating in the Repair Cafe (Fig. 4).
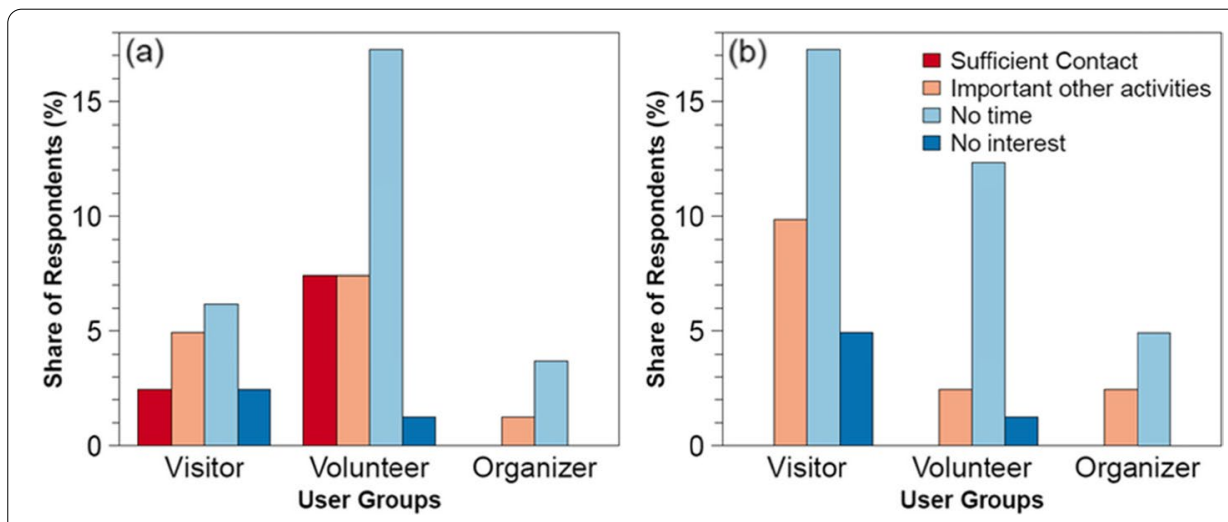

Fig. 4 Barriers for increasing participation in the Repair Cafe by share of respondents and user group. Chart (a) is male respondents. Chart (b) is female respondents 
A partial explanation for the differential in male and female desire to participate further in the Repair Cafe may be the unequal power relationship between the genders within the Repair Cafes, which were observed particularly in the male-dominated Repair Cafes (such as FN2, FN9, and FN10). During participant observations, we observed subtle discouragement of female visitors such as being subjected to 'mansplaining' and a female researcher was referred to as 'little girl' rather than by name. Further, male volunteers appeared to be more likely to encourage male visitors to attempt to personally repair their items than the female visitors which is in contrast to the stated goals of the Repair Cafe networks to empower people to start repair on their own (Netzwek Reparatur-Initiativen 2017). For their part, the interviewees explained away the general unsociability of some of the volunteers as nerdiness: 'The basic type of a Repair Café volunteer is like a nerd that has rather problems with social interaction, I guess' (IN2). Identifying the volunteer group as nerdy and geeky is an expression of non-female masculinities (Zékány and Cerwonka 2011).

Women who volunteered with the Repair Cafes were often seen performing the stereotypical female roles of ensuring a nice atmosphere and offering food and drink. This is similar to the gendered division of labor Rosner (2014) found among repair movements in California. This highlights the role of women within the Repair Cafe as taking care of the more menial tasks which allow for the often male technical volunteers to perform the role of 'expert.' In both RC9 and RC5, female volunteers repaired clothing further emphasizing stereotypical gendered division of the work within the Repair Cafe movement.

In contrast to the issues described above is the Repair Cafe that was exclusive to women (RC11). Interviewees said that this Repair Cafe was founded because of the male-dominated Repair Cafes where women often find themselves unwelcome. In RC11 the user group roles were not as predefined. Thus, everybody helped with the food, everybody asked everybody for help, and visitors helped other visitors with repairs. As an example of the fluidity of the roles, during one participant observation, the organizer could not be present on that day and a volunteer was able to step into that role.

Integrating different social classes was also seen as a problem in some of the initiatives (FN5, FN7, FN10, FN13). Interviewees from the RC7 in particular, which is supported by a university, said that its reliance on the university acted as a deterrent to non-academics and students from participating. Some Repair Cafes (RC 6, 7, 8) struggled to include all social classes as visitors as well as volunteers. Nonetheless, one organizer (IN1) reported success in recruiting unemployed technicians to their Repair Cafe. While Fig. 1b gives the impression of a fair number of indigent and low income individuals who participate in the Repair Cafe (20\% of total respondents indicated they had no net income), observations of the Repair Cafe indicate a high number of students and retirement age individuals are boosting this number for whom income may not be indicative of their social class. However, the higher level of education of the volunteers compared to the visitors (Fig. 2) is indicative of class differences between the two groups. For example, around $70 \%$ of the volunteers have a bachelor's/master's degree in comparison to around $50 \%$ of the visitors. The lower socio-economic status of the visitors, when compared to the volunteers, indicates that again hegemonic masculinity of an "expert" technician volunteer has a role in discouraging less educated from participation.

The Bike Repair Cafe, which focused on refugee integration, had the least problems integrating different social classes. The Bike Repair Cafe was open only to asylum 
seekers from Monday to Thursday, and on Fridays, the Repair Cafe was open to everyone to repair their bikes. Money raised on Fridays is used to finance the repairs for the refugees. The Bike Repair Cafe organized events to specifically integrate the refugees, like bike excursions, joint dinners, parties, etc. Additionally, two refugees became technical volunteers in the Repair Cafe and one was given a part-time job (up to $450 €$ per month) and was, therefore, present almost every day in the Repair Cafe. Thus, because of this specific effort and focus on integrating refugees the Bike Repair Cafe was better able to integrate lower social classes into their Repair Cafe than other Repair Cafes.

The differences in power among the different roles, coupled with a lack of mobility and differences in gender makeup, contribute to a situation where a fixed group of mostly male 'experts' have more say in the shared vision of the Repair Cafe than the mostly female visitors which use the service. On top of this, the differences in social class between those with power within the Repair Cafes and those without further emphasizes the power differences among the different groups within the Repair Cafes.

\section{Discussion}

The Repair Cafes have inconsistencies between their visions for their movement and their practices making it difficult for Repair Cafes to achieve their envisioned sustainability transition (Fig. 5). The Repair Cafes have inconsistencies between their visions for their movement and their practices. While the visions of change within the Repair Cafes (described in Competing narratives section) are reflective of current transition theory, they also emphasize a need for as many people as possible to participate in the Repair Cafe for the transition to happen. However, the way Repair Cafes run in practice with the power dynamics between the different user groups and exclusivity of volunteer positions due to the hegemonic

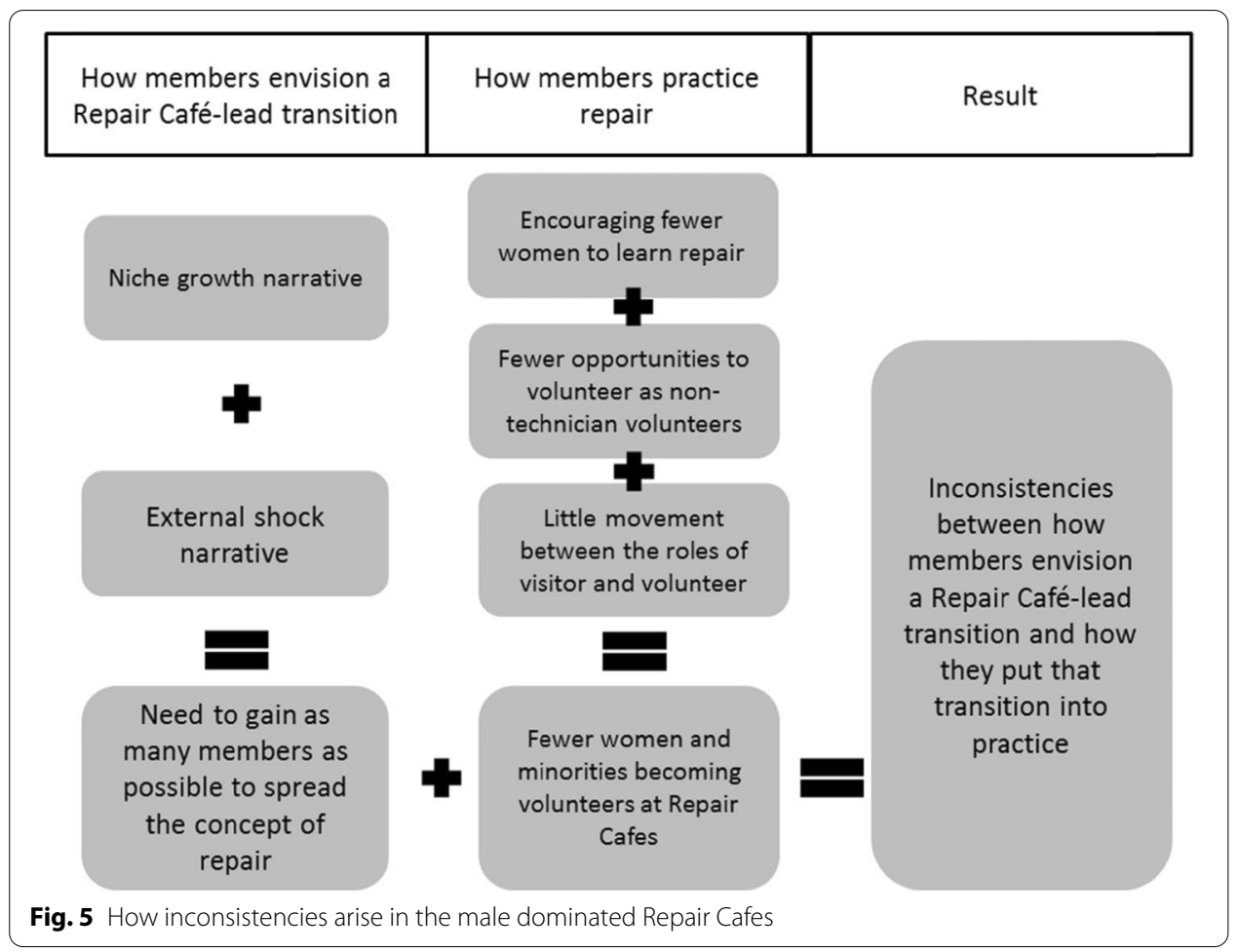


masculinity of "expert" male technicians discourages the participation of women and lower social classes. This means that the Repair Cafes will have difficulty expanding their movement to those groups and limit their ability to grow in numbers. Thus, the way the Repair Cafes practice their movement works against what they are trying to achieve.

Two distinct narratives were voiced by members of the Repair Cafes: the niche growth narrative and the external shock narrative. Both narratives of change expressed by the interviewees are reflective of different aspects of current transition theory. In particular, the niche growth narrative reflects a 'transformation pathway' (Geels and Schot 2007) since this narrative sees the Repair Cafes as practicing alternatives and growing to the point that it forces the regime to adopt repair practices. The external shock narrative is closest to the 'de-alignment and re-alignment' or the 'technological substitution' pathway (both touched upon in Competing narratives section) depending on how optimistic the individual interviewee was about the potential of the movement to grow. This is because the external shock narrative believes that an outside force would need to shock the regime before it would adopt repair.

Both narratives emphasize the need for Repair Cafes to have as many people as possible participate which leads us to explore who participates in Repair Cafes and what role they play within the Repair Cafes. The role of volunteer within the Repair Cafes was dominated by men, whereas the less influential role of visitor was dominated by women (Fig. 1a). This is stark since in other contexts women are more likely to volunteer than men (Steinberg et al. 2002; Bryant et al. 2003; Mesch et al. 2006; Taniguchi 2006). Through interviews and participant observations we discovered that women and those of lower social classes experienced an underlying form of discrimination where they were discouraged from full participation which in turn limits the growth of the Repair Cafes. Technology and heavy tools are perceived in society as masculine (Oudshoorn et al. 2004; Faulkner 2000; Mellström 2002; Oldenziel 1999) which perhaps influences the volunteers' encouragement of male visitors over their female counterparts to negative effects. Additionally, the rigidity of the roles within most Repair Cafes but fluidity in the female-dominated Repair Cafe shows that the hierarchy is likely in place to exclude women and lower-class individuals.

Repair Cafes, themselves have 'innovative power' a constructive power (Avelino and Rotmans 2009) to create resources from broken items that would otherwise become trash. Yet, internally in many Repair Cafes, the user groups use 'systematic power' to maintain a system where men have the innovative power to create these resources, and women and minorities are discouraged from participating in this innovative power. The membership and power structure within Repair Cafes are dominated by educated men. As such, this can limit their alternativeness since the predominant group in power is continuing to exercise that power and the Repair Cafes are reflective of societal gender norms and stereotypes. Privileged males as the group with the most power in society as a whole have the most to lose through achieving the equality needed for a just transition to take place. Thus, Repair Cafes like many other grassroots initiatives fail to include lower social classes and lack diversity (Seyfang and Haxeltine 2012; Smith 2011) which may, in turn, limit the ability of the initiatives to develop truly radical ideas (Becker et al. 2018). Past research has shown that the pursuit of hegemonic masculinities has costs and consequences for those involved (Bufkin 1999; Messerschmidt 1997; Messner 1992). In this 
case, we found that through enacting hegemonic masculinities, the Repair Cafes are hurting their movement.

One potential upside to the exclusionary practices of the Repair Cafes is that by reproducing the hegemonic masculinities of the regime, they may in effect be making the movement more palatable to the mainstream. Boyer (2015) argues that grassroots innovations need to both be not too radical, but still alternative to the regime. In this way, the Repair Cafes are alternative in their repair activities but mainstream in the treatment of women and minorities. There is a debate among researchers as to whether mainstreaming is good for initiatives (Smith 2007) since community-based initiatives have different characteristics than other innovations (Seyfang and Haxeltine 2012) and little research has been conducted on how these initiatives may affect the mainstream (Seyfang and Longhurst 2013). However, as these practices are working against a sustainable and just transition by way of reinforcing a regime that already practices gender discrimination and exclusion of minorities, the Repair Cafes are perhaps working more towards an unjust transition where issues of climate change are tackled without addressing the unequal impacts of climate change across gender and class groups (Hemmati and Rohr 2007; Grineski et al. 2012). This would likely be more acceptable to those in power within the Repair Cafes, ie. privileged men. Additionally, while it would be appealing to see the demographic disparities between the different user groups within the Repair Cafes as a place where the privileged served those less fortunate since the volunteers offer a service to the visitors, it is the reasons for these disparities that negate this. Since the less privileged are discouraged from participating (such as not being taught to repair their items) it is harder for them to have a say in and shape the Repair Cafes as well as any transition which would result from them. It is also possible that the reason that fewer women are technical volunteers is that women are less interested in repairing items than men. However, it is also that society discourages them from perusing those techniques much like how girls are discouraged from perusing STEM careers through subtle discouragement and biased beliefs that girls are not as capable as boys (Lavy and Sand 2015) and indeed certain types of tools are associated with masculinity (Lupton 1993). If this is the case then the Repair Cafes are part of the problem since they are also discouraging subtly women through their behaviour by encouraging more men than women to attempt repairs when they say they need as many people as possible to participate.

Interestingly, the practices of the Repair Cafes more closely align with the external shock narrative than the niche growth narrative. This may be because the people with the most voice within the Repair Cafes, the mostly male volunteers, favor the external shock narrative. From the literature, we know that for the niche to formulate common goals, the members need to have a sense of belongingness (Geels and Raven 2006). Because the (mostly female) visitors are more lacking in a sense of belonging than the (mostly male) volunteers, their visions are underrepresented. Since this narrative is not as focused on the agency of the Repair Cafes, but instead on an outside force influencing the regime, it could explain the lower emphasis Repair Cafes seem to place on gaining every member possible to challenge the regime. The demographics of the Repair Cafes, in terms of both who participates in the Repair Cafes and which positions they hold within the Repair Cafe, influences whose vision is adopted by the Repair Cafes as their collective narratives of change. Repair Cafes, as niche spaces, 
exist within the context of the current regimes and landscapes and they thus often reflect the same power structures; namely, they are dominated by privileged white men which have more of a voice within the organization than women and minorities.

Future research could explore how best Repair Cafes could improve their internal gender relations. Moreover, while this article was able to identify the institutionalization of hegemonic masculinities with RCs as a potential problem, future research could seek to quantify the degree to which it helped or hurt the RCs, as well as the degree to which the RCs are aware of class and gender issues. Future research could also examine if other community-based initiatives have similar sexist practices which hurt their movements or if Repair Cafes in particular are susceptible to it due to societal stereotyping of repairing as a male pursuit. Furthermore, we examined primarily the formal ideal roles of the participants; future research could examine more soft power, for example, volunteers refusing to show up if they dislike the direction of the Repair Café. This research was only conducted on Repair Cafes in the German city of Berlin and thus, future research could examine whether similar user group dynamics cause similar problems in Repair Cafes in other localities. Moreover, our research was limited to 12 case study Repair Cafes due to limits in time and money, future research could expand upon our work examining more Repair Cafes.

\section{Recommendations and further research}

Since Repair Cafes believe that their power comes from having many people repair items and that they do not currently have enough people participating to affect change, it stands that the initiative should undertake actions that encourage participation and inclusion of anyone with an interest in repair. However, their exclusionary practices, whether intentional or not, prevent them from acquiring as many members as they possibly could. This hurts the Repair Cafes and their innovative practices of repairing from gaining momentum and institutionalizing so that they may challenge the regime. By failing to include women and lower social classes fully as volunteers within Repair Cafes, the Repair Cafes are again limiting the full potential of the Repair Cafes not only in terms of growth but also in fostering more sustainable consumption patterns and sustainable transformation. For example, a recent study highlights that promoting gender equality can contribute to achieving sustainable development as a whole (Anderson et al. 2021). Nevertheless, some Repair Cafes were better than others at incorporating women and minorities as members, namely those with a younger membership. This could perhaps reflect slowly changing social norms.

However, the inconsistencies between the Repair Cafes narratives and their practices should be, where possible, rectified if they wish to increase their ability to contribute their innovation of repair to a sustainability transition as envisioned. To attempt to correct this, we draw several recommendations for the Repair Cafes:

1. Inviting more women and minorities to become volunteers. Studies indicate that simply being asked greatly increases the chance that someone will volunteer (Musick et al. 2000).

2. More actively teaching repair to visitors with a particular focus on teaching female visitors to attempt to correct the gender imbalance. 
3. Creating roles within the Repair Cafe that are outside of the organizer and technician volunteer role, such as teaching roles or organizational roles. This could help reshape the understanding of roles within the Repair Cafes as shown in the women's only Repair Cafe (RC11).

4. Recognizing and making use of the types of repair that the visitors are familiar with If the issue is simply a lack of training in newer technology, willing visitors could become volunteers with little training.

5. Allowing visitors to have more say in how the Repair Cafe functions and thus more power. Offering additional formats, such as workshops or talks (such as occurred in the Bike RC), or opening hours adapted to the needs of women, minorities, and lower classes may allow the Repair Cafes to further build relationships with the visitors.

6. Having someone within the Repair Cafe who is responsible for advocating for women, minorities, and lower social classes.

In addition, funders and facilities hosting Repair Cafes could encourage Repair Cafes to undertake actions that would be more inclusive of women, lower classes, and minorities. They could do this by making it a requirement for funding or using the facility, although attaching requirements to funding can pose risks (Becker et al. 2018). Alternatively, funders could offer separate grants specifically to support Repair Cafes in including women, minorities, and lower classes.

Lastly, researchers can use the finding that hegemonic masculinities and discrimination hurts Repair Cafes to better understand how internal dynamics of communitybased initiatives affect their overall ability to contribute to a transition. This knowledge highlights the fact that initiatives exist within a societal context and often recreate the inequalities of that society. Researchers should consider whether other societal structures influence grassroots initiatives negatively.

\section{Appendix}

Table 2

\section{Acknowledgements}

The authors would like to thank the anonymous reviewers for their time and effort on this paper. We would also like to thank Keshav Parajuly for his constructive comments.

Table 2 List of qualitative interviews

\begin{tabular}{lll}
\hline Interview & Repair Cafe & Position within RC \\
\hline Interview 1 & Green RC & Organizer \\
Interview 2 & Green RC & Technical volunteer \\
Interview 3 & Organized RC & Technical volunteer \\
Interview 4 & Organized RC & Visitor \\
Interview 5 & Organized RC & Organizer \\
Interview 6 & Green RC & Organizational volunteer \\
Interview 7 & Green RC & Visitor \\
Interview 8 & Bike RC & Organizer \\
Interview 9 & Bike RC & Technical volunteer \\
Interview 10 & Bike RC & Visitor \\
\hline
\end{tabular}




\section{Authors' contributions}

ES did the original interviews and research as part of a master thesis to which SB and PP acted as supervisors. SB rewrote the thesis into the article and contributed the theory section which was part of her PhD thesis. PP developed the figures. All authors read and approved the final manuscript.

\section{Funding}

Open Access funding enabled and organized by Projekt DEAL.

\section{Availability of data and materials}

This research was based on interviews and surveys and as such the data is not publically available to maintain anonymity of the interviewees.

\section{Declarations}

Competing interests

Not Applicable.

Received: 31 March 2021 Accepted: 14 February 2022

Published online: 07 March 2022

\section{References}

Anderson C, Denich M, Warchold A, Kropp JP, Pradhan P. A causal systems model to understand interactions among the sustainable development goals. Sustain Sci. 2021.

Argüelles L, Anguelovski I, Dinnie E. Power and privilege in alternative civic practices: examining imaginaries of change and embedded rationalities in community economies. Geoforum. 2017:86:30-41.

Avelino F, Rotmans J. Power in transition: an interdisciplinary framework to study power in relation to structural change. Eur J Soc Theory. 2009;12(4):543-69.

Becker SL, Franke F, Gläsel A. Regime pressures and organizational forms of community-based sustainability initiatives. Environ Innov Soc Transit. 2018;29:5-16.

Becker SL. From regimes to grassroots innovations: a framework for understanding the causes of the barriers to communitybased initiatives and their impacts on transitions: PhD diss., University of Potsdam; 2017.

Boyer RHW. Grassroots innovation for urban sustainability: comparing the diffusion pathways of three ecovillage projects. Environ Plan A. 2015;47(2):320-37.

Bryant WK, Jeon-Slaughter H, Kang H, Tax A. Participation in philanthropic activities: donating money and time. J Consum Policy. 2003;26(1):43-73.

Bufkin JL. Bias crime as gendered behavior. Soc Justice. 1999;26(1 (75)):155-76.

Bulkeley $\mathrm{H}$, et al., editors. Cities and low carbon transitions, vol. 35: Routledge; 2010.

Celata F, Dinnie L, Holsten A. Sustainability transitions to low-carbon societies: insights from European community-based initiatives; 2019. p. 909-12.

Connell RW, Messerschmidt JW. Hegemonic masculinity: rethinking the concept. Gend Soc. 2005;19(6):829-59.

Devine-Wright P. Think global, act local? The relevance of place attachments and place identities in a climate changed world. Glob Environ Chang. 2013;23(1):61-9.

Faulkner W. The power and the pleasure? A research agenda for "making gender stick" to engineers. Sci Technol Hum Values. 2000;25(1):87-119.

Flick U, von KardorffE, Steinke I. Qualitative forschung. Theorie, Methoden, Anwendung in Psychologie und Sozialwissenschaften. Reinbek: Rowohlt; 2010. p. 227.

Frantzeskaki N, et al, editors. Urban sustainability transitions: Taylor \& Francis; 2017.

Fuenfschilling L, Frantzeskaki N, Coenen L. Urban experimentation \& sustainability transitions; 2019. p. 219-28.

Geels FW. Technological transitions as evolutionary reconfiguration processes: a multi-level perspective and a case-study. Res Policy. 2002;31(8-9):1257-74.

Geels FW. From sectoral systems of innovation to socio-technical systems: insights about dynamics and change from sociology and institutional theory. Res Policy. 2004;33(6-7):897-920.

Geels FW. The multi-level perspective on sustainability transitions: responses to seven criticisms. Environ Innov Soc Transit. 2011;1(1):24-40

Geels FW. Regime resistance against low-carbon transitions: introducing politics and power into the multi-level perspective. Theory Cult Soc. 2014;31(5):21-40.

Geels FW, Schot J. Typology of sociotechnical transition pathways. Res Policy. 2007;36(3):399-417.

Glaser BG. Doing grounded theory: issues and discussions: Sociology Press; 1998.

Glaser BG. All is data. Grounded Theory Rev. 2007;6(2):1-22.

Grin J, Rotmans J, Schot J. Transitions to sustainable development: new directions in the study of long term transformative change: Routledge; 2010.

Grineski SE, Collins TW, Ford P, Fitzgerald R, Aldouri R, Velázquez-Angulo G, et al. Climate change and environmental injustice in a bi-national context. Appl Geogr. 2012;33:25-35.

Hargreaves, Tom, Alex Haxeltine, Noel Longhurst, Gill Seyfang (2011). Sustainability transitions from the bottom-up: civil society, the multi-level perspective and practice theory. No. 2011-01. CSERGE working paper.

Hemmati M, Rohr U. A huge challenge and a narrow discourse-ain't no space for gender in climate change policy? Women Environ Int Mag. 2007;74:5 
Herrero M, et al. Articulating the effect of food systems innovation on the sustainable development goals. Lancet Planet Health. 2020.

Kannengießer S. Repair Cafés as communicative figurations: consumer-critical media practices for cultural transformation. In: Communicative figurations. Cham: Palgrave Macmillan; 2018. p. 101-22.

Landholm DM, et al. Climate change mitigation potential of community-based initiatives in Europe. Reg Environ Chang. 2019;19(4):927-38.

Lavy V, Sand E. On the origins of gender human capital gaps: short and long term consequences of teachers' stereotypical biases. No. w20909: National Bureau of Economic Research; 2015.

Lupton E. Mechanical brides: women and machines from home to office: Princeton Architectural Press; 1993.

Markard J, Truffer B. Technological innovation systems and the multi-level perspective: towards an integrated framework. Res Policy. 2008:37(4):596-615.

Mellström U. Patriarchal machines and masculine embodiment. Sci Technol Hum Values. 2002;27(4):460-78.

Mesch DJ, Rooney PM, Steinberg KS, Denton B. The effects of race, gender, and marital status on giving and volunteering in Indiana. Nonprofit Volunt Sect Q. 2006;35(4):565-87.

Messerschmidt J. Crime as structured action: gender, race, class, and crime in the making: Sage; 1997.

Messner MA. Power at play: sports and the problem of masculinity: Beacon Press; 1992.

Misoch S. Qualitative interviews. De Gruyter Oldenbourg; 2015.

Musick MA, Wilson J, Bynum WB Jr. Race and formal volunteering: the differential effects of class and religion. Soc Forces. 2000;78(4):1539-70.

Netzwek Reparatur-Initiativen (2017). Gesamtübersicht Initiativen. Reparatur-Initiativen. https://www.reparatur-initiativen.de/ seite/ueber-uns/. Accessed 5 May 2017.

Oldenziel R. Making technology masculine: men, women and modern machines in America: Amsterdam University Press; 1999. p. 1870-945.

Oudshoorn N, Rommes E, Stienstra M. Configuring the user as everybody: gender and design cultures in information and communication technologies. Sci Technol Hum Values. 2004;29(1):30-63.

Raithel J. Quantitative Forschung. Wiesbaden: VS Verlag für Sozialwissenschaften; 2008.

Remap (2018). Dein Weg zu Zero Waste. https://www.remap-berlin.de. Accessed 12 Jan 2018.

Rosner DK. Making citizens, reassembling devices: on gender and the development of contemporary public sites of repair in northern California. Publ Cult. 2014;26(1 (72)):51-77.

Rotmans J, Kemp R, Van Asselt M. More evolution than revolution: transition management in public policy. Foresight. 2001;3(1):15-31.

Schäfer M, et al. Facilitating low-carbon living? A comparison of intervention measures in different community-based initiatives. Sustainability. 2018;10(4):1047.

Schippers M. Recovering the feminine other: masculinity, femininity, and gender hegemony. Theory Soc. 2007;36(1):85-102.

Sekulova F, et al. A 'fertile soil' for sustainability-related community initiatives: a new analytical framework. Environ Plan A. 2017;49(10):2362-82.

Seyfang G. Community action for sustainable housing: building a low-carbon future. Energy Policy. 2010;38(12):7624-33.

Seyfang G, Haxeltine A. Growing grassroots innovations: exploring the role of community-based initiatives in governing sustainable energy transitions; 2012. p. 381-400.

Seyfang G, Longhurst N. Desperately seeking niches: grassroots innovations and niche development in the community currency field. Glob Environ Chang. 2013;23(5):881-91.

Seyfang G, Smith A. Grassroots innovations for sustainable development: towards a new research and policy agenda. Environ Polit. 2007;16(4):584-603.

Smith A. Transforming technological regimes for sustainable development: a role for alternative technology niches? Sci Public Policy. 2003;30(2):127-35.

Smith A. Translating sustainabilities between green niches and socio-technical regimes. Tech Anal Strat Manag. 2007;19(4):427-50.

Smith A, Raven R. What is protective space? Reconsidering niches in transitions to sustainability. Res Policy. 2012;41(6):1025-36.

Smith A. The transition town network: a review of current evolutions and renaissance. Soc Mov Stud. 2011;10(01):99-105.

Steinberg KS, Rooney PM, Chin W. Measurement of volunteering: a methodological study using Indiana as a test case. Nonprofit Volunt Sect Q. 2002;31(4):484-501.

Stitching Repair Café (2017). About Repair Café. Available online at: https://repaircafe.org/de/. Accessed 7 Feb 2017.

Taniguchi H. Men's and women's volunteering: gender differences in the effects of employment and family characteristics. Nonprofit Volunt Sect Q. 2006;35(1):83-101.

Verbong G, Geels F. The ongoing energy transition: lessons from a socio-technical, multi-level analysis of the Dutch electricity system (1960-2004). Energy Policy. 2007:35(2):1025-37.

Zékány É, Cerwonka A. The gendered geek: performing masculinities in cyberspace. Unpublished Masters Dissertation. Budapest: Central European University; 2011.

\section{Publisher's Note}

Springer Nature remains neutral with regard to jurisdictional claims in published maps and institutional affiliations. 